\title{
2019: The Year in Disaster Health and Medicine Research
}

\author{
Samuel J. Stratton, MD, MPH
}

With the close of the year 2019, a look at research in disaster health and medicine (disaster health) shows progress in research quality and, in some circumstances, persistent problems when compared to other specialized areas of health and medicine. A positive aspect of 2019 was the increased number of journals that publish disaster health research. Disaster health has progressed from an area of little scientific interest in the mid-twentieth century to one in which papers are frequently published in major world journals. In addition, international journal index services recognize up to eight journals dedicated in whole or in part to regular publication of disaster health and preparedness research.

Disaster health is a new field of science when compared to other fields in health and medicine. Typically, science in a new area evolves from work done at lower level research methods with higher potential for bias and confounding to more systematic comparative research. Less rigorous research is essential for developing an overall science base for a field, because early research helps establish hypotheses, controversial areas, and a technical language for subsequent development of advanced methods research. Considering that disaster health is in the early phases of developing a science base, the field advanced well in 2019 with published work that has adopted systematic research methods such as the format encouraged by the International Committee of Medical Journal Editors $(\mathrm{ICMJE})^{1}$ and the PRISMA Guidelines for Systematic Reviews. ${ }^{2}$

Challenges exist for disaster-based research that make traditional controlled studies and trials difficult. Disaster events are predictable, but occur in an unexpected and uncontrolled manner that limits the ability to design prospective studies. To address this challenge, disaster researchers are designing comparative simulation research methods based on data and experience described in published observational studies. Designing accurate and realistic disaster simulation is becoming a sub-category in the overall field of disaster research. Another challenge in disaster research is data gathering during actual events that allows for original research or a means to validate simulation studies. Standard data collection systems with defined data elements have been introduced and refined. In disaster health research, both the Health Disaster Management Guidelines for Evaluation and Research in the Utstein Style (with updates) and the Utstein-Style Template for Uniform Data Reporting of Acute Medical Response in Disasters have been important resources for standardized data collection and definition of data elements. ${ }^{3,4}$

Despite disaster health research advances made in 2019, there are problems to note. Survey-based research continues to dominate the type of studies published in the discipline (Table 1). Based on a review of abstracts available on the US National Library of Medicine PubMed index ${ }^{5}$ for studies relying on survey methods research, less than $16 \%$ of the survey research published uses randomization methods for selecting study participants.

\begin{tabular}{|c|c|c|}
\hline Type of Publication & Number & $\begin{array}{c}\text { Percent of Total } 566 \\
\text { Indexed Articles }\end{array}$ \\
\hline Comparative Studies/Trials & 10 & $1.8 \%$ \\
\hline Systematic Reviews & 12 & $2.1 \%$ \\
\hline $\begin{array}{l}\text { Observational/Descriptive } \\
\text { Studies }\end{array}$ & 151 & $26.7 \%$ \\
\hline Case Reports/Field Reports & 6 & $1.1 \%$ \\
\hline Survey Research & 186 & $32.9 \%$ \\
\hline Expert Consensus & 63 & $11.1 \%$ \\
\hline Narrative Review & 40 & $7.1 \%$ \\
\hline Concept Paper & 78 & $13.8 \%$ \\
\hline $\begin{array}{l}\text { Letters/Comments/ } \\
\text { Editorials }\end{array}$ & 20 & $3.5 \%$ \\
\hline Total $=$ & 566 & $100.1 \%$ \\
\hline
\end{tabular}

Table 1. Types of Disaster Health and Medicine Publications Indexed in 2019 by PubMed Central ${ }^{5}$

The lack of randomized methods for selecting participants included in survey-based research leads to high bias potential and unmeasurable confounding of study results. ${ }^{6}$ In addition, a similar abstract review revealed that only $23 \%$ of literature reviews followed standard systematic review guidelines that are defined by the PRISMA Group ${ }^{2}$ or the Cochrane Collaboration. ${ }^{7}$

Expert opinion research is frequent in disaster health research (usually based on the Delphi Method). As a specialized form of survey research, it is important that "expert" participants be selected in a systematic manner to avoid bias and unidentifiable errors that affect study results. In review of indexed disaster health expert opinion research done in 2019, it was noted that most commonly, experts' selection was not described and appeared to be based on non-systematic techniques. If survey-based research and expert opinion research are combined, $44 \%$ of all published disaster health articles published would be included. As noted, few of these types of research publications used techniques for participant selection that avoid bias, confounding, and selection error.

An encouraging point is that disaster health publications in 2019 included comparative studies and systematic reviews that adopted rigorous methods standards. Additionally, published observational-descriptive studies, case reports, and field reports were published that allow for future synthesis of data that has the potential for reviews that focus on the clinical and planning aspects for disaster work. When comparing the various types of disaster health publications with those generally published in the health and medical literature, there is little variation from the ratio of applied research to concept and opinion type papers (Table 1). 
2019 shows encouraging advances in disaster health research. While there is room for improving the quality and rigor of disaster health research, it is now appropriate to consider disaster health research as a legitimate area for scientific exploration. A field of research that is maturing for future scholars to dedicate their attention.

\section{References}

1. Recommendations for the Conduct, Reporting, Editing, and Publication of Scholarly Work in Medical Journals. International Committee of Medical Journal Editors website. http://www.icmje.org/icmje-recommendations.pdf. Accessed December 30, 2019.

2. Liberati A, Altman DG, Tetzlaff J, et al. The PRISMA Statement for Reporting Systematic Reviews and Meta-Analyses of studies that evaluate health care interventions: explanation and elaboration. PLoS Med. 2009;6(7):e1000100.

3. Sundnes KO, Birnbaum ML, International Steering Committee of the Task Force on Quality Control of Disaster Management. Health disaster management guidelines for evaluation and research in the Utstein Style. Prehospital and Disaster Medicine. 1999;17(s3):1-177.
4. Debacker M, Hubloue I, Dhondt E, et al. Utstein-Style template for uniform dat reporting of acute medical response in disasters. PLOS Currents Disasters. 2012;4.

5. PubMed. US National Library of Medicine website. https://www.ncbi.nlm.nih.gov/ pubmed/. Accessed December 30, 2019.

6. Stratton SJ. Assessing the accuracy of survey research. Prehosp Disaster Med. 2015;30(3):225-226.

7. New Cochrane Handbook for Systematic Reviews of Interventions. Cochrane Library 2019 website. https://www.cochrane.org/news/new-cochrane-handbook-systematicreviews-interventions. Accessed December 30, 2019.

doi:10.1017/S1049023X20000011 